important as either technical or economic aspects of pasture improvements.

A stimulating chapter by A. S. Thomas on ecology and human influence raises some important issues for all those interested in studying climax vegetation as a standard against which we may compare other ecosystems. He elaborates the concept that the climax theory has slowed down progress in ecological understanding, and observes that many forest areas regarded as climaxes are proving to be nothing of the sort. The notion that climaxes exhibit the greatest diversity of species is challenged, and various ways in which man modifies ecosystems discussed. There is a revealing comparison of ten general descriptions of the same region written between 1863 and 1962, only two of which, one early and one late, are in recognisable agreement. Thomas concludes that "careful records like those of early explorers could be used for the study of future changes. Such records would be in conformity with the true meaning of ecology - the study of living organisms and their relationships to their surroundings.'

THANE RINEY

\title{
Plants of the World Vols I \& II, The Higher Plants, by H. C. D. de Wit. Thames \& Hudson, 4 gns each. \\ European Alpine Flowers in Colour, by T. P. Barneby. Nelson $70 \mathrm{~s}$.
}

Mountain Flowers in Colour, by Anthony Huxley. Blandford, 30s.

Wild flowers offer a greater scope for superbly illustrated books than almos $t$ any other subject, and these three take full advantage of the opportunities. $\mathrm{Mr}$ de Wit's, originally published in the Netherlands in 1963, has evidently been specially adapted for British readers, with a paragraph about each family in Britain, either wild or in cultivation; and while these descriptions often read as if the author were better versed in books about wild flowers than about wild flowers in the field, they are certainly a useful feature. The plan is to discuss all the gymnosperms (conifers) and angiosperms (flowering plants) family by family, leaving the lower plants (ferns, fungi, mosses and lichens) to a third volume. The book is therefore valuable as a work of reference as well as for its fine colour and monochrome photographs.

The two books on alpine flowers complement each other admirably, and should both be in the baggage of all flower-loving visitors to the mountains of Europe, although only Mr Huxley's will slip easily into the pocket when you get there. Mr Barneby has taken all the 575 superb colour photographs himself, but he covers only the Alps, and is not fully comprehensive even there. Mr Huxley, on the other hand, has produced an indispensable vade-mecum describing all the flowering plants and ferns of the mountains of western Europe, from the Pyrenees to the Julian Alps and Scandinavia, illustrating over 1200 of them, 884 in colour. So while, if you can only buy one it must be Mr Huxley's, Mr Barneby supplements him so admirably that you might buy his book for your wife while you are about it.

RICHARD FITTER

\section{Handbook of New Guinea Birds, by Austin L. Rand and E. Thomas Gilliard. Weidenfeld \& Nicolson, $£ 66$ s.}

This is an excellent example of the modern type of handbook, as distinct from a field guide, condensing within one cover a great part of what is known about the birds of an area. A vast amount of information is packed into it, though one could wish that the short introductory chapter giving the geographical and climatic background, an account of the composition of the New Guinea avifauna, and a short summary of bird migration and breeding seasons in New Guinea, were a bit 
families and species of New Guinea birds, with their known distribution and longer. The main part, nearly 600 pages, comprises a systematic account of all the subspecific variation (if any). It is a good feature that nesting and displays where known are given such thorough treatment; for instance, the summaries of the displays of each species of bird of paradise - New Guinea's chief glory, both in beauty and evolutionary interest - are a most valuable feature of the book.

The illustrations, by two artists, are rather mixed, both in style and conception. Five attractive coloured plates by Albert E. Gilbert show 27 species, and 48 pages of half-tone plates show 129 species, giving 156 species illustrated out of a total of about 650 . The half-tone plates give the impression of being chosen rather haphazardly: those by Douglas E. Tibbitts are stilted compared with Gilbert's, though all appear adequate for identification. It may have been deliberate policy, but it seems a pity to illustrate well-known species of wide distribution such as the oystercatcher and little ringed plover, rather than typically Papuan species which cannot be found elsewhere.

Tom Gilliard's sudden death at the age of 53, soon after the manuscript was completed was a great loss to New Guinea ornithology, and especially to the study of the birds of paradise; he had been responsible for much of our knowledge of these superb birds and would surely have discovered more if he had lived.

D. W. SNOW

\section{Birds of South Vietnam, by Philip Wildash. Charles E. Tuttle, $\$ 7.50$ US.}

The author has long served in the British Foreign Office, including several years in Saigon. He is a laudably social-minded ornithologist, founder of both the Cyprus Ornithological Society and the Ornithological Society of Vietnam. This book is itself a form of social service, in that it is patently a first effort, largely based on other work no longer available, notably that of Jean Delacour - who writes a Foreword of proto-Gaullist egocentricity.

Compiled for his own use, the book is compressed and impersonal, but basically to the point. There is no word of the war, or its huge effects on bird and all other wild life, e.g. from American defoliation chemicals. It is a devoted effort to produce a practical, effective, slightly larger-than-pocket book, and the colour plates, a joint effort by author and wife, help in this effect. The outline drawings are dashing, but some colour values seem to have suffered in reproduction. More important, neither in the text nor on the plates is there ever any indication of bird size, a defect that is accentuated by strange scale effects on several plates, where large birds are shown smaller and vice versa. There is also an annoying tendency to devote illustration space to very well-known birds rather than especially Vietnamese ones. The selection of these illustrations implies some publisher influence, and this is emphasised on the book's front cover, which proclaims other countries 'covered' by the book, North Vietnam, China, Burma, etc. to Borneo. It is true there is considerable species overlap, but in the text there is no attempt to indicate - even by an asterisk - any distribution outside South Vietnam.

Let us hope the FO keeps the Wildashs in Saigon, and that rockets permit a revised second edition of a brave venture, ignoring the publisher's sales ploy for the goose-lover or Borneo boy.

TOM HARRISSON

\section{Birds in the Balance by Philip Brown. Deutsch, 25 s.}

Philip Brown was for many years an official of the Royal Society for the Protection of Birds and for the last eleven of those years their Secretary; now he is editor of the Shooting Times. Has he defected to the 'other side'? Sensibly he 